\title{
Why Research Productivity Among Women in Academia Suffered During the Early Stages of COVID-19 Crisis: A Qualitative Analysis
}

Agata A. Lambrechts ${ }^{1}$, Pipiet Larasatie ${ }^{2}$, Stefani Boutelier ${ }^{3}$, Hala A. Guta ${ }^{4}$, Iwona LeonowiczBukała $^{5}$, Alpha Martinez-Suarez ${ }^{6}$, Shikha Prashad ${ }^{7}$

${ }^{1}$ Department of Education, University of York, York, UK

${ }^{2}$ Department of Wood Science and Engineering, Oregon State University, Corvallis, OR, USA

${ }^{3}$ Aquinas College, Grand Rapids, MI, USA

${ }^{4}$ Qatar University, Doha, Qatar

${ }^{5}$ Faculty of Media and Social Communication, University of Information Technology and Management in Rzeszow, Rzeszow, Poland

${ }^{6}$ Department of Bicultural-Bilingual Studies, University of Texas at San Antonio, San Antonio, TX, USA

${ }^{7}$ Department of Kinesiology and Educational Psychology, Washington State University, Pullman, WA, USA

Correspondence concerning this article should be addressed to Agata A. Lambrechts, Department of Education, University of York, Heslington, York YO10 5DD, UK. Email: aal513@york.ac.uk 


\begin{abstract}
The discourse on research productivity during the early months of COVID-19 has been dominated by bibliometric and quantitative studies highlighting the fewer publications from women scholars compared to men, but few considered the reasons behind this phenomenon. This paper offers new empirical insights into the experiences and perceptions of women scholars during the early stages of the pandemic using the feminist standpoint theory approach to understand why they have been seemingly less productive. Our findings, based on 101 qualitative survey responses, illustrate the centrality of support with respect to childcare, professional-emotional support from peers and mentors that were lost. Restricted access to institutional facilities, resources, loss of structure, additional time required to prepare for online teaching, and increased service load have negatively impacted research productivity. These factors are compounded by poor mental health with high cognitive and emotional tolls, resulting in depleted resources for the intellectually demanding research activities. Conversely, some women scholars, particularly those without care responsibilities, reported reduced commutes, fewer meetings, and flexible working hours, resulting in unchanged or increased research productivity. As the impact of the pandemic is ongoing, it is critical to assess the underlying causes of reduced productivity of women scholars to mitigate these effects.
\end{abstract}

Keywords: Research productivity, women in academia, gendered academia, higher education, COVID-19 pandemic 


\section{Introduction}

On the 11th of March 2020, the World Health Organization (WHO) declared the COVID19 outbreak a global pandemic (WHO, 2020). This paper examines the experiences of women academics during the first five months of the pandemic. During this time, many countries implemented lockdowns and stay-at-home orders, forcing many professionals to work from home (Hickman \& Saad, 2020). While our research is ongoing, this paper examines the participants' experience in the first stage of the pandemic, when the circumstances were new for them, their families, and higher education (HE) institutions. The impact on HE was profound, yet commentary and national policies during that early time focused primarily on the considerable financial challenges facing institutions and implications for students (Aucejo et al., 2020; Thatcher et al., 2020). The impact of the pandemic on academic staff and faculty received far less attention, especially within the first few months of the pandemic.

Academics had to move to virtual instruction almost overnight and maintain scholarly activity and service while also managing increased responsibilities of childcare, homeschooling, eldercare, and other obligations at home (Guy \& Arthur, 2020; Augustus, 2021). While these circumstances affected all staff, the crisis exposed and reinforced existing gender inequalities in HE (Aiston \& Jun 2015; King \& Frederickson, 2021). Evidence suggests that women academics, especially those with young children, experienced a disproportionate decline in the amount of time they were able to devote to research early in the pandemic compared to men and colleagues without children (Myers et al., 2020; EIGE, 2020; OWSD, 2020; Shalaby et al., 2021). This decline is reflected in the number of research outputs. Women submitted and published fewer preprints and manuscripts since the outbreak of the pandemic, and the proportion of solo- or first-authored papers by women fell (Andersen et al., 2020; Dolan \& Lawless, 2020; 
Frederickson, 2020; Gabster et al., 2020; Pinho-Gomes et al., 2020; Ribarovska et al., 2021). Women reported that they found meeting deadlines related to grant and fellowship proposals, projects, and reports harder to meet (Staniscuaski et al., 2020). Within the framework of the socalled prestige economy of higher education (Blackmore, 2012), where 'prestige' is linked to 'research productivity,' publishing in high impact journals, and securing grants, rather than teaching or service (Marginson, 2014), these disparities in the short and mid-term may lead to long-term consequences. These repercussions affect women academics' employability and career trajectories, potentially reversing the positive gains of the last few decades, further exacerbating the underrepresentation (Colby \& Fowler, 2021; Snyder et al., 2019), lower-income (Gabster, 2020), and slower promotion of women in senior faculty positions (Stewart et al., 2009). Thus, it is urgent to explore, understand, and mitigate the different factors affecting academic women's research productivity during the current crisis.

Prior research has attempted to explain the gendered impact of the pandemic by relying on the mechanisms underlying the existing gender gaps in productivity (Pinho-Gomes et al., 2020; King \& Frederickson, 2021). We considered our findings given these previous studies and adopt a feminist lens to provide qualitative empirical evidence about the impact of the pandemic on women scholars, focusing on their lived experiences and perceptions of the initial impact of the pandemic on HE, and considering their social roles in and outside of academia. Our data provide a valuable explanation of why women in the United States and across the world were seemingly less productive (in terms of research output) during the early stages of this crisis (i.e., through the middle of August 2020), highlighting the need for institutional support and understanding during future performance assessments. We provide rich descriptions of factors contributing to declining productivity early in the pandemic that institutions, in the US and 
across the world, may consider when developing policies to support women scholars to create an environment where their research productivity can flourish both during and beyond the pandemic.

\section{Literature Review}

\section{Defining Research Productivity}

Productivity, the ability to perform in relation to specific goals and objectives, is the primary indicator of any production system (Abramo \& D'Angelo, 2014). The definitions and indicators of 'research productivity' in academia vary (Ross \& Donnellan, 1994; Camatini et al., 2015), as do approaches to evaluating productivity, using parametric or nonparametric analytical tools (Daraio, 2019). Under the 'publish or perish' survival paradigm (Gianola et al., 2020; McGrail et al., 2006), the key metric is the number of publications reporting new knowledge and ideas (Ramsden, 1994; Dwyer et al., 2012; Litwin, 2012), also used as a proxy for impact, another key metric of research performance (Camatini et al., 2015). This view takes into account the number of publications, specifically in reputable peer-reviewed journals, that are distinguishable by their impact on the field, measured through the journal impact factor and hindex (Pendlebury, 2009).

Within the prestige economy in HE, research productivity measured through publications reflects the inward and outward perceptions of academic worth and the perceived success of scholars (Aiston \& Jung, 2015). The scholar's publications are considered by leadership when selecting candidates during the hiring process and are important considerations in promotion, tenure, and professorial appointments (Grapin et al., 2013). Ramsden (1994) noted that the 
number and quality of publications are also a critical measure of institutional excellence, included in national and international rankings (see also Aiston \& Jung, 2015).

\section{Gender Disparities in Research Productivity}

Although gender disparities in the publishing of research outputs have decreased over time, they continue to persist (De Kleijn et al., 2020). Several studies have investigated this gap and found that these disparities are affected by pervasive institutionalized biases. For example, women are less likely than men to be invited to co-author manuscripts (Teele \& Thelen, 2017), especially as part of international collaborations (Araújo \& Fontainha, 2017; Kwiek \& Roszka, 2020), and in particular early in their careers (McDowell et al., 2006). If women do collaborate on publications, they are more often middle authors, reflecting their lower academic positions, which negatively affects their performance, reinforcing their lower status and rank (Van den Besselaar \& Sandström, 2017). Women are also less likely to be cited (Potthoff \& Zimmermann, 2017; Maddi et al., 2019), especially by men (Maliniak et al., 2013), receive less grant funding (Oliveira et al., 2019) to carry out research and 'buy out' their time from teaching and service responsibilities, and face biases in peer review (Helmer et al., 2017; Severin et al., 2020). Women are held to a higher standard and, thus, take up to half a year longer than men to get published (Hengel, 2017). Symonds et al. (2006) suggested that the current method of measuring research productivity (i.e., the h-index) is in itself strongly biased against women researchers because it focuses on quantity, instead of quality, of published outputs.

The larger proportion of women in teaching-intensive and part-time positions (Eagly, 2020) and the shorter career duration also explain the gender gap (Huang et al., 2020). This is further correlated with family formation, as Cech and Blair-Loy (2019) have found in STEM 
research in the US, where $43 \%$ of women, compared to $23 \%$ of men, leave full-time employment after having their first child. In addition, leaving the academic workforce entirely is highly correlated with childbearing (Kahn \& Ginther, 2015).

\section{Existing Research on the Impact of the Pandemic on Research Productivity}

Sparked by early anecdotal accounts from journal editors who expressed that women authors have been submitting fewer manuscripts, while men have substantially increased their submissions since the beginning of the pandemic (Flaherty, 2020), several studies providing evidence for this phenomenon have been published. Andersen et al. (2020) compared the gender distribution of authorship in medical COVID-19 papers during 2020 with other articles published in the same journals in 2019 in the US $(n=1,893)$. The women's share of authorship in COVID19 papers (as first authors) decreased by $19 \%$ overall, with particularly fewer submissions from women as first authors in March and April 2020. Similar trends globally were reported, for example, by 1) Pinho-Gomes et al. (2020), who compared the gender distribution of authorship of COVID-19 research in PubMed as of May 2020 (n=1370); 2) Vincent-Lamarre et al. (2020) who reviewed submissions to 22 cross-disciplinary repositories and three platforms for registered reports indicating initiation of new research projects; 3) Amano-Patiño et al. (2020) who reviewed economics working papers; and 4) Cui et al. (2020) who examined the Social Science Research Network, the largest open-access preprint repository for social science. In all studies, the authors found a drop in submissions by women or lower submission levels than expected. Their findings also suggest that junior and mid-career researchers have been affected more than senior scholars. 
A few studies have adopted other methods to examine the research productivity of scholars during this crisis: Kim and Patterson (2020) analyzed 1.8 million tweets by approximately 3000 political scientists. They found that the gap in publishing work-related tweets between women and men academics had tripled since the beginning of the pandemic. In contrast, family- and caregiving-related tweets increased amongst women academics during the same period compared to men, and particularly in junior academic women. Kappel et al. (2021) used a quantitative survey of lockdown experiences of graduate researchers and faculty (globally) with 210 responses, including $78 \%$ by women. They found that female participants reported "more personal changes affecting their ability to work than male respondents" (p.1). Staniscuaski et al. (2020) survey of Brazilian academics' experiences $(n=3,345)$ in early 2020 reported that academic parents, particularly white mothers of young children and Black women in general, were submitting fewer manuscripts than planned. Myers et al. (2020) used a crosscountry survey of principal investigators in the United States $(n=4,535)$ and found that women (particularly those with young children) experienced a substantial decline in the time they were able to devote to research; this gender difference in the number of hours devoted to research has also been documented by others (Shalaby, 2021; Bender et al., 2020; Brown et al., 2021; Duncanson \& Weir, 2020; Organization for Women in Science for the Developing World, 2020).

The initial literature offered a limited perspective on productivity conditions, only exploring women's experiences as caretakers in qualitative terms (Buckle, 2021; Guy \& Arthur, 2020; Minello et al., 2020). Minello et al. (2020) interviewed 25 academic women with children in the US and 13 in Italy as part of a larger study on the social effects of the COVID-19 crisis. Their findings suggest that in both national contexts, academic caregivers prioritized teaching over research. The move to online teaching and lack of time (or focused time) on research led to 
anxiety about the ability to publish and, in turn, fear about future career progression (Minello et al., 2020; Bender et al., 2020; Brown et al., 2021).

Much of the above-cited literature is based on a bibliometric data analysis of preprint publications and manuscript submissions. Most of these studies are limited by disciplinary or national contexts, and some focus on a particular subject area or journal. There has been considerable consensus thus far, cutting across all fields and geographic locations, that women scholars' research productivity has been affected disproportionately compared to men. While these studies have not examined the reasons why women scholars are publishing less, some authors hypothesized that additional responsibilities at home, including childcare and homeschooling, are one of the primary reasons (Pinho-Gomes et al., 2020; King \& Frederickson, 2021). Childcare responsibilities intersect with more teaching, administrative, and professional (i.e., non-research) duties, particularly for junior women in academia (Amano-Patiño et al., 2020; King \& Frederickson, 2021). Women academics are also more likely to be in a dual-career relationship with another academic (King \& Frederickson, 2021), competing for research time at home. Against this backdrop, we set out to investigate the experiences of women with and without children during the early stages of the pandemic to understand why women in academia across the world are seemingly less productive (in terms of research output) during the current crisis. We focused on their lived experiences and perceptions of the impact of the pandemic on HE. While we intend to include the perspectives of all those who experience bias and disadvantage in academia as members of marginalized genders, all but two of our participants (who did not disclose their gender) self-identified as women. Therefore, the findings reported in this paper center on the experiences of women. 


\section{Materials and Methods}

This research study comes from data collected on the first phase of a larger project, titled “Gendered Academic Productivity During a Worldwide Pandemic: The Impact of the Coronavirus on Scholarship in Higher Education." Our research group (COVID G.A.P., Www.covidgap.co.uk) consists of 15 women scholars from across the world (as named in the acknowledgments) who came together during the onset of the pandemic. Having met online in a Facebook group, I Should Be Writing (ISBW), owned and managed by Cathy Mazak, we formed a collaboration to explore the lived experiences and perceptions of our fellow academic women and non-binary scholars recruited from within the group[1]. This paper has been written by a subgroup of international researchers from within that larger collaboration.

\section{Theoretical Position}

In this paper, we consider the broader context of the often-conflicting professional and personal demands experienced by women scholars within higher education (and the wider societal context) as a result of enduring patriarchal patterns. We take the feminist standpoint theory approach (Harding, 1988) to make the often invisible work of women in academia visible, and to document the specific challenges (and benefits) during a global crisis of COVID-19, by exploring the lived experiences and perceptions of women scholars in the US and around the world (Davis \& Hattery 2018; Social Sciences Feminist Network Research Interest Group [SSFNRIG], 2017). In accordance with the standpoint theory, we believe that at least some of the challenges, struggles, and conditions experienced by women during this time are unique to us and as such, unlikely to be experienced and thus considered by institutions where women remain confined to relatively limited roles, and not the most senior positions. As 'rules of the game' in 
the culture of measurement and audit in HE (including those relating to research productivity) "lurk[ing] beneath the surface rationality of academic meritocracy" (Morley, 2012, p.116) are reinforcing the patriarchal ways in $\mathrm{HE}$, we, as women scholars ourselves, engage in the examination and "analysis of these conditions in order to change them" (Potter, 2006, pp. 131132).

\section{Research Design}

We employed a descriptive design utilizing an online fully qualitative questionnaire via Qualtrics (Qualtrics, Provo, Utah, USA) that included 27 demographic questions and ten openended questions about research productivity, professional and personal circumstances during the pandemic. The benefit of using a qualitative questionnaire instead of interviews is that it can be delivered across a wider population with asynchronous delivery/response. Having considered the cross-national scope of our study and thus the time zones across which not only we as researchers are spread, but so are our participants and more importantly, not wanting to add on 'yet another meeting' to the already busy schedules of our participants, we decided to utilize questionnaires instead of semi-structured interviews.

Online questionnaires as a research tool are not often used in qualitative studies, dominated by interviews. However, Braun et al. (2020) argue that "qualitative surveys are compatible with research embedded in broadly qualitative research values or paradigms" (p. 2) and can be used "to harness the potential qualitative data offer for nuanced, in-depth and sometimes new understandings of social issues" (p.2). While we acknowledge the relative disadvantage of not being able to probe and ask follow-up questions, we note that responses to 
our questions were often several paragraphs long, included detailed and complex accounts "of the type of sense-making typically of interest to qualitative researchers" (Braun et al., 2020, p.2).

As is typical for qualitative studies (we did not aim to conduct any quantitative analyses of our findings), we did not form a hypothesis, instead seeking to explore the personal experiences and impressions held by participants (Bryman \& Bell, 2007, Saldaña, 2004, Saunders et al., 2009). The open-ended questions related to scholarly identity, daily routines, impact on primary relationships, and challenges of balancing the pressures of scholarly activity with other competing family and work demands. Here, we describe the overarching research question of this project that examined academic and research productivity in the context of persistent gender disparities within academia. We focused our analysis of the responses to two specific questions:

1. How has the pandemic and the stay-at-home orders affected your scholarly activity?

2. How do you balance the pressures of scholarly activity with competing demands during the pandemic, including, e.g., comparisons with other scholars with or without caretaking demands or in comparison to male-identified colleagues?

\section{Distribution}

The online questionnaire was designed in American English and shared seven times (with permission) with the private ISBW Facebook group members. At the time (as of 20 June 2020), the group had almost 14,000 members from across the globe, identifying as women and nonbinary persons, representing various disciplines and different career stages: from doctoral researchers to professors, all actively engaged in academic scholarly writing and looking for 
professional support in this area. Responses were collected between 1 July and 15 August 2020, providing a snapshot view of the immediate impact of the pandemic.

\section{Participants}

After removing duplicate, blank, and incomplete submissions, the final dataset contained responses from 101 participants. As noted above, all but two participants self-identified as women. Of the sample, $58.4 \%$ were aged between 30 and $39,17.8 \%$ were aged $24-29,18.8 \%$ were aged 40-49, and 5.0\% were 50 or over. Table 1 below describes other key demographic characteristics of the questionnaire sample.

Table 1: Demographics of questionnaire sample.

\begin{tabular}{lc} 
& Percent of Sample \\
\hline Region of residence & \\
North America & $71.3 \%$ \\
Australia & $6.9 \%$ \\
Europe & $12.9 \%$ \\
Africa & $2.0 \%$ \\
Asia & $1.0 \%$ \\
Dependents & \\
$\quad$ Children under 18 at home & $53.5 \%$ \\
Other dependents (including partner/elderly parents) & $9.9 \%$ \\
No children at home and no other dependents & $36.6 \%$ \\
Career stage & \\
Master's students/graduate researcher & $1.0 \%$ \\
Doctoral researcher & $15.8 \%$ \\
$\quad$ Doctoral researcher, including whether other academic posts are & $32.7 \%$ \\
held & \\
Postdoctoral researcher, including whether other academic posts are & $13.9 \%$ \\
held & \\
Assistant Professor/Lecturer/Instructor/Researcher & $56.4 \%$ \\
Associate/Research Fellow & \\
Associate Professor/Senior Lecturer/Senior Research Fellow & $8.9 \%$ \\
Full Professor/Professor & $3.0 \%$ \\
\hline
\end{tabular}

Note: Notably, 29 participants reported having multiple roles within their university or across two or more institutions. 
As the questionnaire made use of optional questions and logic branching, the number of responses for individual questions differed. For the two questions specified above, we received 87 and 76 responses, respectively. We acknowledge that although our study was cross-national in scope and includes participants from several countries and regions, the majority of questionnaire respondents are from, or are based in North America $(+70 \%)$, in particular in the United States $(+64 \%)$.

\section{Data Analysis}

Following the removal of incomplete questionnaire responses, the qualitative data were coded line by line for use in NVivo (QSR International Pty Ltd., 2020). They were analyzed following the thematic network approach as described by Attride-Stirling (2001). The procedure divides the topics present in the text into three groups of themes of different levels: 1) detailed basic themes, 2) organizing themes that are clusters of basic themes, and 3) general/global themes that are the most super-ordinate themes. The themes are then presented as visual, weblike maps illustrating complex relationships between them (Attride-Stirling, 2001).

All authors contributed to the process of thematic coding. The initial coding of about a third of the dataset was completed separately by three members of the team, who inductively developed and refined the codes or basic themes, agreed later on together with the organizing themes, by the whole team. A codebook was then produced to guide re-coding (where necessary) of the initial subset of data. The three coders carried out a case-by-case comparison, and any disagreements were resolved at this stage. If necessary, responses were re-coded to ensure interrater reliability. Following this process, the remaining data were coded. Finally, all authors reviewed the coded data and created the thematic network structure (see Figure 1). 


\section{Results}

As illustrated in Figure 1, two super-ordinate, interconnected global themes explored in this study were support and research productivity. The basic themes have been clustered together into six organizing themes: negative and positive effects, lack of and available support, and the perceived advantage and disadvantage in relation to others. Pseudonyms are included below if chosen by participants; otherwise, position and location are stated where direct quotations are used.

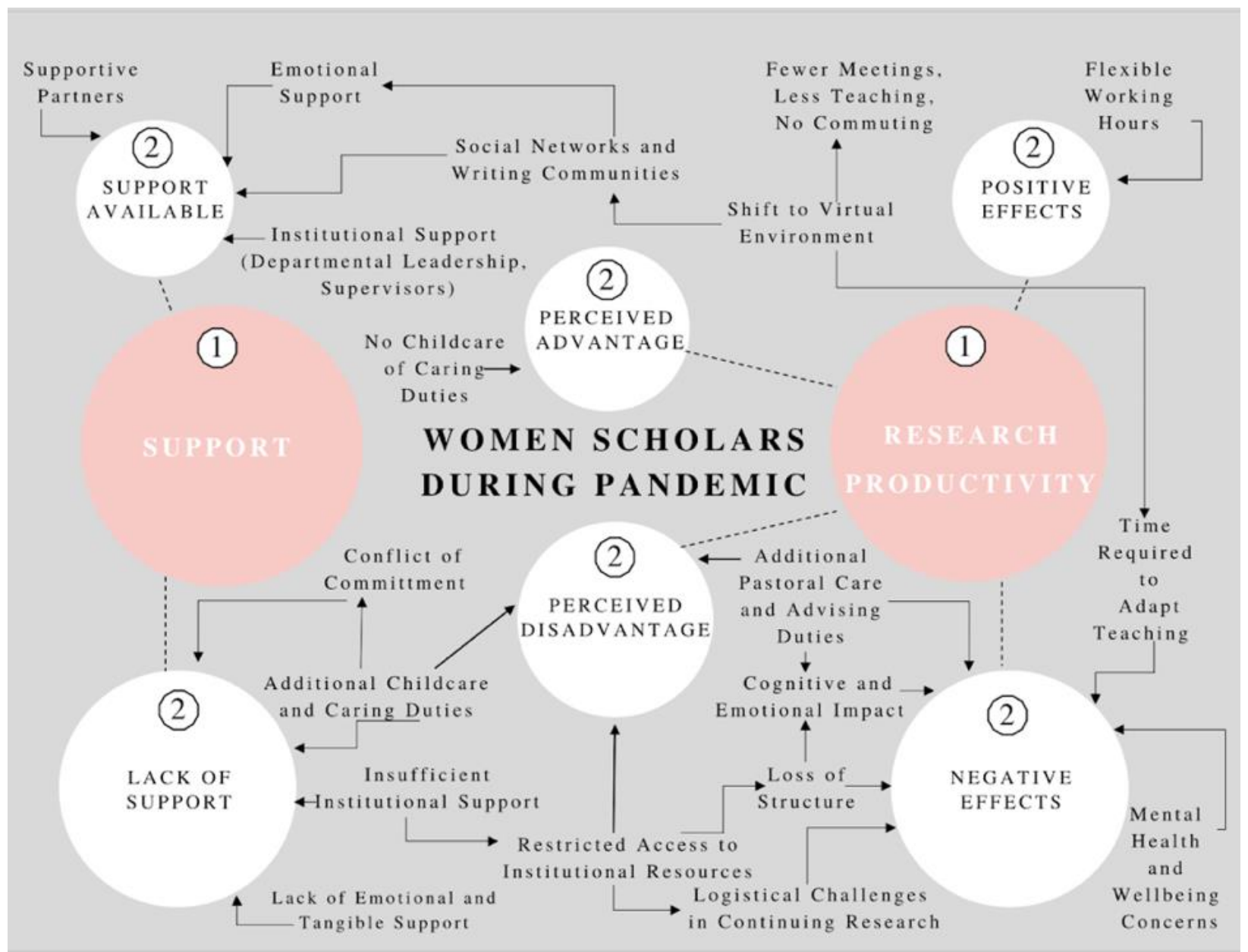

Figure 1: A thematic network of women scholars' research productivity during the COVID-19 pandemic. (1) denotes global themes and (2) denotes organizing themes. 


\section{The Role of Support}

The pandemic and subsequent lockdown affected participants' lives to different degrees. Participants' narratives highlighted the role of support (or lack thereof) in their scholarly productivity. Many participants stated that a loss of support during COVID-19 impacted their productivity negatively. When schools and daycares began to shut down, academic parents and guardians had no alternative childcare support systems to turn to as stayat-home orders meant that no babysitters or family members could be engaged to provide support with caring for children and homeschooling. As an assistant professor and administrator from the US elaborated,

The largest support I've had as a scholar with children has been having full-time childcare outside the home. During the lockdown we were no longer able to utilize child care resulting in my working from home with a toddler. My partner is considered 'essential' so was still working outside the home, leaving me with full time childcare and work responsibilities.

This experience was not unusual, and many parents had no option but to put a pause on their research productivity and shift "from an emphasis on [their] professional role during the day to having [their] mom identity come into full force." As Brianna, a postdoctoral fellow from Canada stated "Increased caregiving responsibilities and the associated logistics, mental stress and generally coping with the pandemic have meant I have done very little writing in recent months and haven't submitted papers or grants that I expected to write".

Many participants felt that institutional support has been inadequate. Amealia, an assistant professor from the US shared, 
As we plan for fall 2020, my institution is requiring that faculty teach in person and have sent out information about accommodation that states the only option for caregivers is unpaid leave (...) Throughout all of this, the system has made very little change, instead choosing to continue on as normal as possible and ask others (e.g., faculty, students) to make 'normal' work during a pandemic.

Indeed, the lack of childcare support coupled with the loss of access to institutional resources has substantially affected women scholars that is likely to have long-term consequences. Ban, a postdoctoral researcher, based in the US relayed,

We faced lockdown for nearly three months, during which I had deadlines for several grant applications (...) Writing grants at home with a small child was counterproductive. My supervisor/mentor allowed me to work for a few hours at the lab to generate some data (...) However, I had to take my child with me to my work (daycares being closed) which was also counterproductive. In short, this pandemic coupled with a near single parent situation has made my future career a bleak and dire scenario.

Even with supportive partners, many female scholars faced similar challenges. Rar from South Africa explained that even with a supportive spouse "My daughter is still breastfeeding and comes to me quite a lot as she constantly wants to drink. I don't think any males have to deal with that sort of neediness/ clinging from their children. I doubt it anyway."

Lack of support did not only affect those caring for children. When stay-at-home orders were placed, many participants could no longer meet with colleagues, mentors, family, and friends in person. Participants reported feeling "isolated", "less connected", "sad", "uncomfortable", "anxious", lacking "emotional and some tangible support", and "miss[ing] seeing colleagues 
every day". According to many participants, the lack of emotional and tangible support negatively impacted their scholarly productivity. Briana, a US-based postdoctoral researcher shared,

Pre-pandemic, I felt like I had a strong team of mentors, a network of mostly far away graduate school friends/colleagues for support, and strong support in my personal life. All of these relationships still exist, but not getting to see any colleagues in person has definitely made things feel disrupted and limited.

While the lack of support negatively affected participants' scholarly productivity, the opposite can be assumed true. Some participants reported some forms of institutional support that were "reasonable and generally supportive to working parents", while others offered a one-year extension to tenure clocks. Although those who indicated receiving extra support were visibly in the minority, the support these participants received "made all the difference" and "kept [them] afloat when [they were] drowning". Daisy, a UK-based lecturer, whose department leadership supported her meeting the deadline for an edited volume "by reallocating some of [her] marking load at a particularly tough time and freeing up some of [her] meeting times/delegating exam board times", stressed that "because of the support, [she] was not as disadvantaged as [she] would have been otherwise." Department chairs and supervisors, who were "extremely understanding", "supportive", and tried to help by reducing or reallocating "non-immediate admin demands", enabled participants to navigate the terrains of emotional labor and stress which accompanied the pandemic. In a few cases, supportive partners also played a role by easing some of the additional demands and making participants "able to cope".

With the shift to online work, technology provided an alternative for those who lost inperson contact with colleagues, friends, and family. Online meetings with colleagues were utilized 
as a source of additional emotional support during the pandemic. Several participants also were a source of support for others, including providing increased pastoral care to undergraduate and postgraduate students and help and encouragement for peers and junior colleagues. Tired Brit, a Doctoral student from the UK, started a Zoom based biweekly doctoral coffee break. Within two months, she created "a solid 20 doctoral students' key support network", "weekly research sounding boards with (...) like-minded PhD students, email exchanges with [her] supervisor and until the end of term, monthly research community meetings."

\section{Effect of the Pandemic Crisis on Research Productivity - Other Factors}

The participants discussed several other prominent factors related to the impact of the pandemic and related stay-at-home orders. A few participants reported maintaining their research productivity at usual levels, while others could write and publish more work than before the pandemic. Those participants come from diverse disciplines and at varying stages of their careers, but most (12 out of 14) have no child caretaking responsibilities. The two parents of those who experienced increased productivity cited their student-centered jobs and heavy teaching load prepandemic as reasons for finding more time for research during the lockdown, despite their caretaking responsibilities. The increased productivity was attributed to the shift to a virtual environment, which led to fewer meetings, less teaching, and no commuting. The flexibility of working from home and the more flexible working hours helped some, as explained by Ana, a Ph.D. student from the UK: "I found that when I'm well-rested and don't try to spend 9 hours in a row focusing, I can do a lot more in the time that [sic] I do spend behind my desk."

Further, with online interactions, some participants found it easier to make new connections, sometimes leading to more effective collaboration - "[The pandemic] has actually 
given me more time (...) to produce work. [I] have made more connections with colleagues online, from work and beyond" (Ellen, a senior lecturer from the UK). However, a vast majority of participants reported on multiple factors that negatively affected their capacity to focus and produce research outputs. These were rarely named in isolation from one another but instead presented as interconnected factors, collectively shaping participants' experiences as women, partners, mothers, caretakers, teachers, and more rarely during the pandemic, as researchers.

Several women described mental health and wellbeing concerns including depression, as well as emotional struggles and difficulties focusing: "[I am] struggling to be able to think clearly", "it [is] incredibly difficult to stay focused while writing and working", "it takes longer and more energy to write." These cognitive difficulties may be related to the omnipresent "general feeling of uncertainty and worry." Although some participants mentioned their mental health concerns preceding the pandemic, their intensity was amplified by the pandemic. Some participants reported that they felt "no motivation" to write or do research "due to general anxiety and emotional exhaustion." Kayla, an assistant professor from the US, reflected on the increased cognitive and emotional toll, explaining: "Even if I set aside time to do research, that curiosity and creativity is gone from my brain."

Other key factors contributing to the negative effect included the conflict of commitment arising from new or additional caretaking responsibilities. Like many other professionals, academics had to manage both caretaking and work from home responsibilities. The demands of full-time parenting, coupled with the swift shift to online teaching, made the participants' predicament even more onerous. Three Hats, who is a full professor, department chair, and a mother, described her experience stating, “(...) all I could do was keep up with teaching, Zoom/Webex meetings for [the] department, and keep my child's schedule (...) I found I was 
much more drained at the end of each day." This experience was shared by many participants, who reported that during the lockdown, their research "took a back burner", "has taken a back seat", took "a major hit", or completely "has ground to a halt". Indeed, "between caregiving [and] supporting students, preparing teaching materials, the exhaustion of Zoom meetings, writing has become a much less significant priority", and many participants reported having "zero time to spend on research". Specifically, the shift to online teaching affected most participants, even those with no childcare or other caretaking responsibilities. Many reported that preparing for online classes was "very stressful" and "time-consuming", making it "almost impossible to write and publish". The almost overnight move to online teaching and working from home on a full-time basis was closely associated with a loss of structure linked to reduced access to institutional facilities for some participants,

I feel like there [i]s always ten other things that I need to be doing. I miss the campus boundaries and the GOING TO WORK because it set clear lines. Of course, I worked at home before, too, but not this much. (Diana, Assistant Professor, US)

While some participants were able to write and publish based on previously collected data, several others noted the impact of logistical challenges related to restricted access to labs, data, software, and other forms of institutional support. Several participants were also worried about their ability to produce research output in the future, as they experienced difficulties collecting new data in a locked-down world. For example, an assistant professor of evolutionary biology shared, "Most of the research that I would have conducted over my primary research season (the summer) was not possible due to the pandemic (...) this has stalled my research program by an entire year (...)."

Some participants, particularly those in early stages of academic careers, worried about 
perceptions of those viewing their work applications and making decisions based on their research productivity "What's tough about this is that I am a full-time adjunct looking for a tenure track position at a time when these roles are hard to come by but also when I am the least research productive." (Nora, Instructor, US). This stress about declining productivity was exacerbated by comparisons with peers whom participants perceived to be more productive than themselves.

\section{Relativity of Experiences and Shifting Focus}

Furthering the findings discussed in Minello et al. (2020), many participants were acutely aware of their relative disadvantage compared to others. We asked participants explicitly to compare their experience to that of colleagues. Many directly compared their experiences to their male colleagues, whom they perceived to be much more productive. Some participants reported that male colleagues had commented on their own "higher levels of productivity" as a result of "all the extra time" and "that it's very productive as their wives tend to look after the kids". As participants compared themselves to their male colleagues, they wrote, "I find this disparity anxiety-provoking" and "[i]t feels like I am falling further and further behind and will never catch up". Some blamed the institutions for encouraging behavior they observe amongst their colleagues:

I don't exactly know how my male colleagues are managing but my sense is that many are so competitive that they see this as a moment where they can thwart competition and come ahead. Universities encourage that type of competitive spirit and elitism (...)" (Irene, assistant professor from the US)

Mara, an associate professor from the US, noted frustrations with "male, especially senior 
colleagues who have used this as a sabbatical and have not focused attention on supporting more junior scholars or those of us that [have] substantial caretaking responsibility", suggesting a confounding effect of one's career stage.

Another strong theme was a comparative measure not between genders but between those with and without caretaking responsibilities. Alice, who is a $\mathrm{Ph} . \mathrm{D}$. candidate and was writing her dissertation at the time, wrote, "My (childless) committee talked to me via [Z]oom about how they had so much time and how I must be getting so much writing done" and Peyton who was also writing her Ph.D. dissertation stated, "those without caretaking demands may find it difficult to understand the constantly changing roles of those of us who are taking care of others throughout the pandemic." Multitasking roles during the pandemic have returned to "all of the unpaid labour that often falls to women is doing so again, but now it's doing so without any of the support structures that most of us have managed to set up over the years." We acknowledge that without a comparison of male experiences, it is difficult to fully comprehend the comparison of productivity during COVID-19 as a gendered impact versus the shifting roles of caretaking support.

Many participants made no direct comparison to any colleagues $(11.8 \%)$ or chose not to compare themselves (10.9\%). This may have been due to small department sizes, non-gendered collegial camaraderie, or being removed from a physical environment of comparison (e.g., seeing when a colleague arrives and leaves). Others understood the likely disadvantage further down the line in their career but argued that we cannot go on as normal "trying to pump out research as if nothing is going on in the world". Instead, they describe ways in which the ongoing crisis has helped them to stop and re-evaluate their priorities and shift their focus away from the neverending race to publish. Hermoine, a full professor from the US explained, 
Would I get more done without a child around? Sure. But would I be having as much fun? No. (...) Back in April my daughter was trying out a new recipe from TikTok and she said, "this is me, living my best pandemic life." I loved that. And it was a major mind shift for me. I want to live my best pandemic life - doesn't matter what other people are doing $(\ldots)$.

Kayleigh, a US-based postdoctoral researcher, elaborated that the pandemic helped her embody the different dimensions of her identity, rather than defining herself as only a scholar:

I don't envy male-identified colleagues nor scholars who are not caretakers for a parent. They may be able to have more time to be productive, but is that really the most important thing in life? I don't think so. I am very passionate about my career and my work. I identify and hold closely my identities as a scholar and an intellectual. However, my work does not wholly define me. I am also a daughter, a dog-mom and cat-mom, a great listener, a member of the queer community, a gardener, a Black Lives Matter ally and activist, and so much more.

Further, Hermione, who is a full professor, reported that the pandemic caused her to shift the focus of her research and scholarly activity from publication and career advancement to a more tangible impact on her community and students:

Yes, my scholarly activity was impacted. But honestly for the better! I'm setting up a food pantry and will be able to ensure that students in crisis can get free food - how awesome is that? Way better than writing an article that 10 people read. 


\section{Discussion}

COVID-19 has brought many challenges for academics worldwide. While the evidence on research productivity during this time is still being gathered, early reports suggest the impact of the pandemic has been unequal, exposing and compounding existing gender inequalities in HE, and our research sought to understand the reasons behind it. Our findings support the theory that having children and family caretaking duties in accordance with traditional gender roles is a decisive factor that influences research productivity, inhibiting women from competing fairly in the prestige economy of HE, where 'prestige' is largely based on publishing in high-impact journals and securing grants (Marginson, 2014). Confined at home, with greater caretaking responsibilities, and deprived of institutional support, a clear majority of our participants struggled to conduct research and write manuscripts and funding applications during the first months of the pandemic. These short-term issues will lead to long-term consequences for women's careers in higher education as the inability to collect data and start new projects will likely inhibit publishing opportunities further down the line.

Our findings illustrate the centrality of support amongst the conditions for continued research productivity of women scholars, primarily in US higher education. This relates to structures of support around childcare and family life, as well as professional and emotional peer and mentor support, typically available within institutions, and finally, the institutional support itself. The 'second shift' burden affecting academic women has been discussed in the literature prior to the pandemic (Berggren, 2008; SSFNRIG, 2017). Results from Alon et al. (2020) indicate that before the pandemic, women in academia and beyond were performing a majority of childcare, about $60 \%$ if married and part of a dual-earning household. Early findings on the pandemic impact on gender equality (Adams-Prassl et al., 2020; Alon et al., 2020) more broadly indicate that women 
have spent more time on childcare while working from home during the pandemic. Our findings corroborate this, with participants reporting sole or a large share of responsibility for care and homeschooling. Past research suggests that women view this extra work as individual responsibility and do not connect potential negatives of the work-life balance to academic disparities (Fotaki, 2013). Conversely, our research suggests that women are frustrated by the prospects of having their research productivity compared to male colleagues and those without children or other caring responsibilities, who they perceive as more productive during this time. These results are consistent with the findings in other recent studies (Minello et al., 2020; Shalaby et al., 2021).

Although some women report supportive and understanding advisors and superiors, many suffer from loss of emotional and tangible support from colleagues and mentors, whom they do not see on campus anymore. Such support is vital, with those working in isolation experiencing lower research productivity (Dever et al., 2006). The importance of this support has been reiterated in our findings. Many women sought to utilize technology for regular meetings with colleagues within their institutions and build online academic support networks, including writing groups. These networks act as a platform to support writing skills and "overcoming writing isolation" and "breaking down the isolation of academic work more generally" (Dwyer, 2012, p. 136).

Our findings also suggest that the effect of the pandemic on research productivity has been positive for some academic women, who benefit from fewer meetings, less commuting, and more flexible working schedules. These participants were primarily students in the dissertation writing stage of their doctoral program without caretaking responsibilities. In addition, another positive outcome manifested for participants representing a larger spectrum of career stages, some of whom used the pandemic as an opportunity to reassess their priorities and embraced their entire 
identities, beyond that of a scholar sprinting from one publication to the next as in the prestige economy of academia's expectations. They found a new motivation to focus and develop their many identities and how their work impacted their students and society. However, a clear majority of our participants reported that the 1) limited access to institutional facilities and resources, and the subsequent 2) loss of structure, coupled with 3) additional time required to prepare for and to facilitate online teaching, meaning it was challenging to continue conducting research and writing. Previous research suggests that one of the main factors influencing success in academic publishing is prioritizing the task of writing (Nygaard, 2017). This has not been possible for many of our participants due to either home care duties or the increased teaching and service workloads. The service work on campus is generally disproportionally allocated to women (Guarino \& Borden, 2017), and it appears that this pattern has been exacerbated during the pandemic. Although our participants saw pastoral care and advising as particularly important and necessary during this time, they also understood that such work is not as highly valued as research and will not help them advance their careers. Finally, deteriorating mental health, caused by the pandemic or amplified by it, stemmed from the increased cognitive and emotional toll of the pandemic, left women scholars with fewer cognitive resources, less ability to focus, and lack of motivation to attend to the highly intellectually demanding activities involved in research and writing.

A limitation of our study was the English-language questionnaire. Although this was appropriate, as our recruitment was limited to members of the ISBW group where all communication is in English, our study was cross-national in scope and includes participants from several countries and regions, the majority of questionnaire respondents are from, or are based in, the United States. While we have not noted any significant differences between reported experiences based on geographical location, we acknowledge that local circumstances may shape 
experiences. Accessing a broader sample of women scholars in different national contexts would further inform the research. In addition, investigating men's perceptions in academia would provide a comparative understanding of their apparent higher research productivity. In light of these limitations, we will include men's perspectives (particularly those with caring responsibilities) in Phase Two of our international study (in English). Further, we have now adapted the survey for national, linguistic, and cultural contexts and are collecting data in other languages and specific national contexts through 'sister projects' in Mexico, Poland, and Qatar (see www.covidgap.co.uk for details). We further acknowledge that for all our participants, other dimensions of social identity intersect with gender; as we believe that capturing and examining these complexities in a single publication in a coherent way is close to impossible, as COVID G.A.P. collaborative we aim to, in further outputs, focus on experiences of particular groups, e.g. partners, parents, graduate students, and disable academics. Finally, while we have examined participants' demographic data, we have not observed any notable differences based on discipline. Although our sample was relatively balanced, we recommend that comparative analyses of different disciplines (and possibly specific institutional contexts, for example, teaching-focused vs. research-intensive or public vs. private) be carried out in the future, perhaps in the form of meta-analyses of local and small-scale studies.

Our data collection in the summer of 2020 provides only a snapshot view of the immediate impact of the pandemic on women scholars' research productivity. During this time, most countries had lifted or begun to lift national lockdowns. Although the period of lockdown in most countries was relatively short in academic terms, the pandemic is ongoing, and the 'crisis' period is far from over (indeed, several countries have imposed lockdowns in response to second and subsequent pandemic waves). Our current analysis provides early 
evidence that can be used to develop a proactive approach to alleviate the disproportionate pressures on women and revitalize their research productivity in anticipation of future consequences. Our ongoing collaboration will examine those medium and long-term ramifications of the early lockdown and the impact of evolving issues specifically for women and non-binary scholars. In doing so, our work will continue to identify factors that contribute to the declining research productivity that may guide institutions to develop and implement policies to support women scholars. 


\section{Acknowledgments}

The authors would like to acknowledge members of the full research team, COVID G.A.P. (Gendered Academic Productivity; listed in alphabetical order) - Anoud Abusalim, Kristina S.

Brown, Sara Bender, Nuchelle L. Chance, Tricia Farwell, Deanna L. Hensley Kasitz, Joanne Hessmiller, and Olga Vega - and thank Cathy Mazak, owner of the private Facebook group, I Should Be Writing, for both providing the space for us to come together and the opportunity to launch the first phase of our research.

\section{Funding}

This research did not receive any financial support.

\section{Declaration of interest}

No potential conflict of interest was reported by the authors.

\section{Author contribution statement}

Study conception and design: AAL, HAG, PL

Acquisition of data: AAL, SB, HAG, PL, IL-B, AM-S, SP

Coding of data: HAG, PL, SP

Analysis and interpretation of data: HAG, IL-B, SB, SP, AAL, AM-S, PL

Drafting of manuscript: Introduction - AAL, IL-B, AM-S; Methods - AAL, IL-B; Findings AAL, HAG, IL-B, SB, SP, AM-S, PL; Discussion and Conclusions - AAL, SP

Critical revision: AAL, SP, SB, HAG, IL-B, AM-S, PL 


\section{Ethics approval}

Approval to conduct the study was granted by the Institutional Review Board of Adler University in Chicago (US) (Protocol number 20-078).

\section{Informed consent}

Informed consent was obtained from all participants included in the study. Names of participants have been changed and no identifying information has been included in this article. 


\section{References}

Abramo, G. \& D'Angelo, C.A. (2014). How do you define and measure research productivity? Scientometrics, 101(2), 1129-1144. https://doi.org/10.1007/s11192-014-1269-8

Alon, T., Doepke, M., Olmstead-Rumsey, J., \& Tertile, M. (2020). This time it's different: The role of women's employment in a pandemic recession. https://www.ipr.northwestern.edu/ourwork/working-papers/2020/wp-20-39.html

Amano-Patiño, N., Faraglia, E., Giannitsarou, C. \& Hasna, Z. (2020). "Who Is doing new research in the time of COVID-19? Not the female economists." Vox EU. https://voxeu.org/article/whodoing-new-research-time-covid-19-not-female-economists

Andersen, J.P., Nielsen, M.W., Simone, N.L., Lewiss, R.E., \& Jagsi, R. (2020). Meta-Research: COVID-19 medical papers have fewer women first authors than expected. eLife, 9 , e58807. http://doi.org/10.7554/eLife.58807

Attride-Stirling, J. (2001). Thematic networks: An analytic tool for qualitative research. Qualitative Research, 1(3), 385-405. https://doi.org/10.1177/146879410100100307

Aucejo, E.M., French, J.F., Araya, M.P.U., \& Zafar, B. (2020). The Impact of Covid-19 on student experiences and expectations: Evidence from a survey. NBER Working paper Series, 27392. https://www.luminafoundation.org/wp-content/uploads/2020/07/theimpact-of-covid.pdf

Augustus, J. (2021). The impact of the COVID-19 pandemic on women working in higher education. Frontiers in Education, 6, 648365. https://doi.org/10.3389/feduc.2021.648365.

Bender, S., Brown, K.S., Kasitz, D., \& Vega, O. (2020). Academic womxn and their children: Parenting during COVID-19 and the impact on scholarly productivity. [Manuscript submitted for publication] 
Berggren, C. (2008). Horizontal and vertical differentiation within higher education: Gender and class perspectives. Higher Education Quarterly, 62(1/2), 20-39. https://doi.org/10.1111/j.1468-2273.2008.00381.x

Braun, V., Clarke, V., Boulton, E., Davey, L. \& McEvoy, C. (2020). The online survey as a qualitative research tool. International Journal of Social Research Methodology, 1-14. https://doi.org/10.1080/13645579.2020.1805550

Brown, K.S., Bender, S., Vega, O., \& Kasitz, D. (2021). Academic womxn and their partners: Impact of COVID-19 on relationships in quarantine and recommendations for couples. Family Relations. [Manuscript accepted for publication]

Bryman, A. and Bell, E. (2007). Business Research Methods (2nd ed.). Oxford University Press.

Buckle, C. (2021). Research during the COVID-19 pandemic: Ethics, gender and precarious work. International Journal of Housing Policy, 1-15. https://doi.org/10.1080/19491247.2020.185790726

Caminiti, C., Iezzi, E., Ghetti, C., De'Angelis, G., \& Ferrari, C. (2015). A method for measuring individual research productivity in hospitals: Development and feasibility. BMC Health Services Research, 15(1), 1-8. https://doi.org/10.1186/s12913-015-1130-7

Cech, E. A., \& Blair-Loy, M. (2019). The Changing Career Trajectories of New Parents in STEM. Proceedings of the National Academy of Sciences, 116(10), 4182-87. https://doi.org/10.1073/pnas.1810862116.

Cui, R., Ding, H. \& Zhu, F. (2020). Gender inequality in research productivity during the COVID-19 pandemic. SSNR Electronic Journal. https://doi.org/10.2139/ssrn.3623492 
Daraio, C. (2019). Econometric approaches to the measurement of research productivity. In W. Glänzel, H.F. Moed, U. Schmoch, M. Thelwall (Eds). Springer Handbook of Science and Technology Indicators. Springer. https://doi.org/10.1007/978-3-030-02511-3_24

Davis, S. H. \& Hattery, A. (2018). Teaching feminist research methods: A comment and an evaluation. Journal of Feminist Scholarship, 15(Fall), 49-60. https://doi.org/10.23860/jfs.2018.15.05.

Dever, M., Morrison, Z., Dalton, B. \& Tayton, S. (2006) "When Research Works for Women.” http://www.adm.monash.edu.au/sss/equity-diversity/assets/docs/wlas/whenresearchworks.pdf.

Dever, M. \& Morrison, Z. (2009). Women, research Performance and work context. Tertiary Education and Management, 15, 49-62. https://doi.org/10.1080/13583880802700107

Dolan, K., \& Lawless, J.F. (2020). It takes a submission: Gendered patterns in the pages of AJPS. https://ajps.org/2020/04/20/it-takes-a-submission-gendered-patterns-in-the-pagesof-ajps/

Duncanson, K., Weir, N., Siriwardhane, P., \& Khan, T. (2020). How COVID is widening the academic gender divide. https://phys.org/news/2020-10-covid-widening-academicgender. html.

Dwyer, A., Lewis, B., McDonald, F. \& Burns, M. (2012). It's always a pleasure: Exploring productivity and pleasure in a writing group for early career academics. Studies in Continuing Education, 34(2), 129-144. https://doi.org/10.1080/0158037X.2011.580734

Edgar, F. \& Geare, A. (2013). Factors influencing university research performance. Studies in Higher Education, 38(5), 774-792. https://doi.org/10.1080/03075079.2011.601811. 
De Kleijn, M., Jayabalasingham, B., Falk-Krzesinski, H.J., Collins, T., Kuiper-Hoyng, L., Cingolani, I., Zhang, J., Roberge, G., Deakin, G., Goodall, A., Bunker Whittington, K..\& Berghmans, S. The Researcher Journey Through a Gender Lens: An Examination of Research Participation, Career Progression and Perceptions Across the Globe (Elsevier, March 2020). www.elsevier.com/gender-report

European Institute for Gender Equality [EIGE]. (2020). Relevance of gender in the policy area. https://eige.europa.eu/gender-mainstreaming/policy-areas/research.

Flaherty, C. (2020). No room of one's own. Inside Higher Education. https://www.insidehighered.com/news/2020/04/21/early-journal-submission-datasuggestcovid-19-tanking-womens-research-productivity.

Fotaki, M. (2013). No woman is like a man (in Academia): The masculine symbolic order and the unwanted female body. Organisation Studies, 34(9), 1251-1275. https://doi.org/10.1177/0170840613483658

Frederickson, M. (2020). Women are getting less research done than men during this coronavirus pandemic. https://theconversation.com/women-are-getting-less-research-done-thanmenduring-this-coronavirus-pandemic-138073

Gabster, B. P., van Daalen, K., Dhatt, R. \& Barry, M. (2020). Challenges for the female academic during the COVID-19 pandemic. Lancet, 395(10242), 1968-1970. https://doi.org/10.1016/S0140-6736(20)31412-4

Gianola, S., Jesus, T. S., Bargeri, S., \& Castellini, G. (2020). Publish or perish: Reporting Characteristics of Peer-reviewed publications, preprints and registered studies on the COVID-19 pandemic. medRxiv. https://doi.org/10.1101/2020.06.14.20130823 
Gibney, E. (2017). Teaching load could put female scientists at career disadvantage. Nature. https://doi.org/10.1038/nature.2017.21839

Grapin, S., Kranzler, J., \& Daley, M. L. (2013). Scholarly productivity and impact of school psychology faculty in APA-accredited programs. Psychology in the Schools, 50(1), 87101. https://doi.org/10.1002/pits.21658

Guarino, C.M. \& Borden, V.M.H. (2017). Faculty service loads and gender: Are women taking care of the academic family? Research in Higher Education, 58(6), 672-694. https://doi.org/10.1007/s11162-017-9454-2

Guy, B. \& Arthur, B. (2020). Academic motherhood during COVID-19: Navigating our dual roles as educators and mothers. Gender, Work and Organization, 27, 887-899. https://doi.org/10.1111/gwao.12493

Harvey, R., Brown, K., Miller, B., Williams-Reade, J., Tyndall, L., \& Murphy, M. (2016). Theory into research practice: reflections and recommendations on collaborative feminist research. Journal of Feminist Family Therapy, 28(4), 136-158. https://doi.org/10.1080/08952833.2016.1235410

Hengel, E. (2017). Publishing while Female. Are women held to higher standards? Evidence from peer review. https://doi.org/10.17863/CAM.17548

Helmer, M., Schottdorf, M., Neef, A., \& Battaglia, D. (2017). Gender bias in scholarly peer review. eLife Sciences, 6, e21718. https://doi.org/10.7554/eLife.21718.001

Hickman, A. \& Saad, L. (2020), Reviewing remote work in the US under COVID-19. Gallup. https://news.gallup.com/poll/311375/reviewing-remote-work-covid.aspx

Huang, J.M., Gates, A.J., Sinatra, R., \& Barabasi, A.L. (2020). Historical comparison of gender inequality in scientific careers across countries and disciplines. Proceedings of the 
National Academy of Sciences, 117(9), 4609-4616.

https://doi.org/10.1073/pnas.1914221117

Kim, E. \& Patterson, S. (2020). The Pandemic and gender inequality in academia. Available at SSRN 3666587. http://dx.doi.org/10.2139/ssrn.3666587

King \& Frederickson (2021) The pandemic penalty: The gendered effects of COVID-19 on scientific productivity. Socius: Sociological Research for a Dynamic World, 7, 1-24. https://doi.org/10.1177/23780231211006977

Litwin, J. (2012). Who's getting the biggest research bang for the buck. Studies in Higher Education, 39(5), 771-785.

Łuczaj, K., Leonowicz-Bukała, I., \& Kurek-Ochmańska, O. (2021). Creative academic transfer in the borderlands. The case of commuting professors in Poland. [Manuscript submitted for publication]

Maddi, A., Larivière, V. \& Gingras, Y. (2019) Man-woman collaboration behaviors and scientific visibility: Does gender affect the academic impact in economics and management? Proceedings of the 17th International Conference on Scientometrics \& Informetrics, 1687-1697.

Maliniak, D., Powers, R. \& Walter, B. (2013). The gender citation Gap in International Relations. International Organization, 67, 889-922. https://doi:10.1017/S0020818313000209

Marginson, S. (2014). University research: The social contribution of university research. In J. C. Shin \& U. Teichler (Eds.), The future of the post-massified university at the crossroads: Restructuring systems and functions (pp. 101-118). Springer. 
McDowell, J. M., Singell, L. D., \& Stater, M. (2006). Two to tango? Gender differences in the decisions to publish and co-author. Economic Inquiry, 44(1), 153-168.

McGrail, MR. Rickard, CM., \& Jones, R. (2006). Publish or perish: a systematic review of interventions to increase academic publication rates. Higher Education Research \& Development, 25(1), 19-35. https://doi.org/10.1080/07294360500453053

Minello, A., Martucci, S., \& Manzo, L.K.S. (2020). The pandemic and the academic mothers: Present hardships and future perspectives. European Societies, 23, S82-S94. https://doi.org/10.1080/14616696.2020.1809690

Morss, K. \& Murray, R. (2001). Researching academic writing within a structured programme: Insights and outcomes. Studies in Higher Education, 26(1), 35-52. https://doi.org/10.1080/03075070020030706

Myers, K. R., Tham, W.Y., Yin, Y., Cohodes, N., Thursby, J. G., Thursby, M. C., Schiffer, P., Walsh, J. T., Lakhani, K. R. \& Wang, D., (2020). Unusual effects of the COVID-19 pandemic on scientists. Nature Human Behaviour, 4, 880-883. https://doi.org/10.1038/s41562-020-0921-y

Nielsen, M.W., Alegria, S., Börjeson, L., Etzkowitz, H., Falk-Krzesinski, H.J., Joshi, A., Leahey, E., Smith-Doerr, L., Williams Woolley, A., \& Schiebinger, L. (2017). Opinion: Gender diversity leads to better science. Proceedings of the National Academy of Sciences, 114(8), 1740-1742. https://doi.org/10.1073/pnas.1700616114

Nygaard, L. (2017). Publishing and perishing: an academic literacies framework for investigating research productivity. Studies in Higher Education, 42(3), 519-532. https://doi.org/10.1080/03075079.2015.1058351 
Oliveira, D. F. M., Ma, Y., Woodruff, T. K. \& Uzzi, B. (2019) Comparison of National Institutes of Health Grant Amounts to First-Time Male and Female Principal Investigators. JAMA, 321(9), 898-900. https://doi.org?10.1001/jama.2018.21944

OWSD. (2020). The impact of COVID-19 on women scientists from developing countries: Results from an OWSD member survey. Availabhttps://owsd.net/resources/newsevents/impactcovid-19-women-scientists-developing-countries-results-owsd-member

Pendlebury, D. A. (2009). The use and misuse of journal metrics and other citation indicators. Archivum Immunologiae et Therapiae Experimentalis, 57, 1-11. https://doi.org/10.1007/s00005-009-0008-y

Pinho-Gomes, A. C., Peters, S., Thompson, K., Hockham, C., Ripullone, K., Woodward, M. \& Carce, C. (2020). Where are the women? Gender inequalities in COVID-19 research authorship. BMJ Global Health, 5(7), e002922. http://dx.doi.org/10.1136/bmjgh-2020002922

Potthoff, M. \& Zimmermann, F. (2017). Is there a gender-based fragmentation of communication science? An investigation of the reasons for the apparent gender homophily in citations. Scientometrics, 112(2), 1047-1063.

QSR International Pty Ltd. (2020) NVivo (released in March 2020), https://www.qsrinternational.com/nvivo-qualitative-data-analysis-software/home Quimbo, M. A. T. \& Sulabo, E. C. (2014). Research productivity and its policy implications in higher education institutions. Studies in Higher Education, 39(10), 1955-1971. https://doi.org/10.1080/03075079.2013.818639

Ramsden, P. (1994). Describing and explaining research productivity. Higher Education, 28, 207-226. https://doi.org/10.1007/BF01383729 
Ribarovska, A. K., Hutchinson, M. R., Pittman, Q. J., Pariante, C., \& Spencer, S. J. (2021). Gender inequality in publishing during the COVID-19 pandemic. Brain, behavior, and immunity, 91, 1-3. https://doi.org/10.1016/j.bbi.2020.11.022

Saldaña, J. (2014). Coding and analysis strategies. In The Oxford handbook of qualitative research. Oxford Press.

Saunders, M., Lewis, P. \& Thornhill, A. (2009). Research Methods for Business Students. Pearsons.

Severin, A., Martins, J., Heyard, R., Delavy, F., Jorstad, A. \& Egger, M. (2020). Gender and other potential biases in peer review: cross-sectional analysis of 38250 external peer review reports. BMJ Open 10, e035058. https://doi.org/10.1136/bmjopen-2019-035058

Shalaby, M., Allam, N., \& Buttorff, G. J. (2021) Leveling the field: Gender inequity in academia during COVID-19. PS: Political Science \& Politics, 1-7. https://doi.org/10.1017/S1049096521000615

Social Sciences Feminist Network Research Interest Group [SSFNRIG]. (2017). The burden of invisible work in academia: Social inequalities and time use in five university departments. Humboldt Journal of Social Relations 39(39), 228-245. https://www.jstor.org/stable/90007882

Stack, S. (2004). Gender, children and research productivity. Research in Higher Education, 45(8), 891-920. https://doi.org/10.1007/s11162-004-5953-z

Staniscuaski, F., Reichert, F., Werneck, F., de Oliviera, L., Mello-Carpes, P.B., Soletti, R. C. Almeida, C. I., Zandona, E., Ricachenevsky, F. K., Neumann, A., Schwartz, I. V. D., Tamajusuku, A. S. K., Seixas, A., Kmetzsch, L., (2020). Impact of COVID-19 on academic mothers. Science, 368(6492), 724. https://doi.org/10.1126/science.abc2740 
Penni, S., Ornstein, M., \& Drakich, J. (2009). Gender and Promotion at Canadian Universities. Canadian Review of Sociology, 46(February), 59-85. https://doi.org/10.1111/j.1755618X.2009.01203.x.

Symonds, M.R., Gemmell, N.J., Braisher, T.L., Gorringe, K.L. \& Elgar, M.A. (2006). Gender differences in publication output: Towards an unbiased metric of research performance. PLoS ONE, 1(1), e127. https://doi.org/10.1371/journal.pone.0000127

Thatcher, A., Zhang, M., Todoroski, H., Chau, A., Wang, J. \& Liang, G. (2020). Predicting the impact of COVID-19 on Australian universities. Journal of Risk and Financial Management, 13, 188. https://doi.org/10.3390/jrfm13090188

Teele, D., \& Thelen, K. (2017). Gender in the journals: Publication patterns in political science. PS: Political Science \& Politics, 50(2), 433-447. https://doi.org/10.1017/S1049096516002985

Warner, T. D., \& Roberts, L.W. (2004). Scientific integrity, fidelity and conflicts of interest in research, Current Opinion in Psychiatry, 17(5). 381-385. https://doi.org/10.1097/01.yco.0000139974.45189.96

World Health Organisation [WHO]. (2020). WHO Director-General's opening remarks at the media briefing on COVID-19:11 March 2020. https://www.who.int/dg/speeches/detail/whodirector-general-s-opening-remarks-at-themedia-briefing-on-covid-19---11-march-2020

Vincent-Lamarre, P., Sugimoto, C.R. \& Larivière, V. (2020). The decline of women's research production during the coronavirus pandemic. https://www.natureindex.com/newsblog/decline-women-scientist-research-publishingproduction-coronavirus-pandemic 